\title{
EFEITO DE CONCENTRAÇÕES DE SOLUÇÃO AÇUCARADA NA ADERÊNCIA DO INOCULANTE TURFOSO ÀS SE MENTES, NA NODULAÇÃO E NO RENDIMENTO DA SOJ $A^{(1)}$
}

\author{
O. BRANDÃO J UNIOR ${ }^{(2)} \&$ M. HUNGRIA(3)
}

\begin{abstract}
RESUMO
A associação simbiótica da soja [Glycine max (L.) Merrill] com bactérias do gênero Bradyrhizobium resulta no processo de fixação biológica do $\mathbf{N}_{2}$. A inoculação com estirpes selecionadas garante a maximização do processo biológico e, no Brasi l, são comercializados, anualmente, quase 13 mil hões de doses de inoculante, a maioria à base de turfa. A adesão da turfa às sementes, porém, é baixa, requerendo o uso de adesivos. A recomendação atual é de uso de solução açucarada (açúcar comercial) a $25 \%$, mas essa concentração poderia reduzir o vigor e aumentar a incidência de doenças nas sementes. Neste estudo, foram testadas, então, doses inferiores a $25 \%$. Confirmou-se que a solução açucarada favorece o processo de inoculação, incrementando em até $90 \%$ a aderência da turfa às sementes e, em casa de vegetação, aumenta a nodulação e as taxas de fixação do $\mathrm{N}_{2}$. Em quatro experimentos realizados em solos com população estabelecida de Bradyrhizobium, a rei noculação da soja com solução açucarada a $10 \%$ resultou em um incremento médio, estatisticamente significativo, de $237 \mathrm{~kg} \mathrm{ha}^{-1}$ de grãos, ou 8,6\%, em relação à rei noculação com água, e de 17,5\%, em relação à população naturalizada do solo, indicando quea concentração de açúcar atualmente recomendada pode ser reduzida para $10 \%$.
\end{abstract}

Termos de indexação: adesi vo, Bradyrhizobi um, fixação biológica do nitrogênio, inoculação, inoculante, nodulação.

\footnotetext{
(1) Parte da Tese de Mestrado do primeiro autor, como parte das exigências do curso de Mestrado em Agronomia da U niversidade Estadual de Londrina - UEL. Recebido para publicação em abril de 1999 e aprovado em maio de 2000.

(2) Engenheiro-Agronômo. Praça Raul Cardoso, n.118, CEP 16200-000 Birigui (SP).

(3) Engenheira-Agronôma da Embrapa Soja. Caixa Postal 231, CEP 86001-970 Londrina (PR).
} 


\title{
SUMMARY: EFFECTS OF CONCENTRATIONS OF SUGAR CANE SOLUTION ON THE ADHESION OF PEAT-BASED INOCULANT TO THE SEEDS, ON THE NODULATION AND SOYBEAN YIELD
}

\begin{abstract}
Soybean [Glycinemax (L.) Merrill] plants establish a symbiosi s with bacteria bel onging to the genus Bradyrhizobium, realizing the biological $\mathrm{N}_{2}$ fixation process. Theinoculation with selected rhizobial strains guarantees the maximization of the biological process. In Brazil, almost 13 million doses of inoculants, mainly peat based, arecommercialized annually. However, the peat adhesion to the soybean seeds is low, requiring the use of adhesi ves. The current recommendation is the use of a water sugar cane solution at $25 \%$, but this concentration could reduce plant vigor and increase seed diseases. Consequently, in this study, lower concentrations were tested. The needs for using a sugar cane solution were confirmed, increasing up to $90 \%$ the peat adhesion to the seeds and, under greenhouse conditions, resulting in higher nodulation and $\mathrm{N}_{2}$ fixation rates. In four field experiments performed in soils with an established population of Bradyrhizobium, the reinoculation with $10 \%$ of sugar cane solution resulted in a mean increase of $237 \mathrm{~kg} \mathrm{ha}^{-1}$ of grains, or $8.6 \%$, in relation to thereinoculation with water, and of $17.5 \%$ in relation to thecontrol with thenaturalized soil population, thereforeindicating that thesugar concentration currently recommended can be decreased to $10 \%$.
\end{abstract}

Index terms: adhesive, Bradyrhizobium, biological nitrogen fixation, inoculation, inoculant, nodulation.

\section{NTRODUÇÃO}

Segundo Burton (1981), as leguminosas desempenham papel crescente como fornecedoras de proteínas para milhões de pessoas, além de aumentar a fertilidade do solo. O sucesso do uso de leguminosas é devido, em grande parte, à sua associação simbiótica com bactérias dos gêneros Allorhizobium, Azorhizobium, Bradyrhizobium, Mesorhizobium, Rhizobium eSinorhizobium. Essas bactérias associam-se às raízes das leguminosas, formando estruturas específicas, os nódulos, onde ocorre o processo de fixação biológica do nitrogênio atmosférico $\left(\mathrm{N}_{2}\right)$ ( $\left.\mathrm{FBN}\right)$.

A soja [Glycine max (L.) Merrill] é o principal produto de exportação da agricultura brasileira eas pressões competitivas enfrentadas no mercado internacional são crescentes (F ontes \& Ferrão, 1990). O Brasil é o segundo maior produtor de soja, sendo responsável por $18,5 \%$ da produção mundial. Noano de 1997, essa leguminosa foi cultivada em mais de 11,0 milhões de hectares, al cançando o rendimento médio de $2.315 \mathrm{~kg} \mathrm{ha}^{-1}$, superior ao rendimento mundial, de $2.107 \mathrm{~kg} \mathrm{ha}^{-1}$ (FAO, 1997). A participação brasileira no comércio dessa leguminosa tem sido grande desde o início dos anos 70, quando os EUA e - Brasil passaram a suprir a maior parte da demanda mundial dos produtos desoja (Roessing \& Guedes, 1993).

A FBN pode representar o fator principal no processo de manutenção da produtividade em solos tropicais (J oly, 1991). Segundo esse autor, é interessante notar que a inoculação do rizóbio não está confinada apenas à introdução de uma planta exótica. A inoculação torna-se necessária, também, quando as estirpes de rizóbios presentes naturalmente no solo são pouco eficientes e devem ser substituídas. Com exceção de al guns casos, como o da soja no Brasil, a técnica da inoculação, de modo geral, ainda é pouco usada. Nos casos em que a inoculação pode aumentar a produção, porém, a eficácia é fortemente dependente da qualidade do produto e do manejo adotado na aplicação do inoculante.

A produção de inoculante é o processo final na pesquisa e desenvolvimento dos estudos de FBN, tecnologia pela qual rizóbios promissores e de alto potencial simbiótico são produzidos em massa e embalados para aplicação nos campos de cultivo (Somasegaran, 1991). Os inoculantes de leguminosas procuram for necer um meio de transporte adequado dos rizóbios fixadores de $\mathrm{N}_{2}$, da fábrica para as leguminosas no campo. A qualidade do veículo usado para carregar a bactéria (turfa, líquido, etc) e a aplicação adequada do inoculante visam manter e distribuir, de forma conveniente e econômica, uma população el evada de rizóbios efetivos e eficientes (Smith, 1995).

A turfa constitui um dos melhores substratos para a elaboração de inoculantes comerciais e sua utilização está condicionada à sua disponibilidadee custo (Ronchi \& Balatti, 1991). Entretanto, al gumas turfas não atingem as especificações de um bom veículo, cujas qualidades desejadas são: al ta retenção 
de umidade, facilidade de processamento, ausência detoxidez para a bactéria, facilidade deesterilização, disponibilidade em grande quantidade, baixo custo e boa adesão às sementes (Burton, 1981). A turfa em pó desprende-se facilmente das sementes e a adição de adesivos melhora a sua fixação (Smith, 1995), mas requer uma etapa a mais no processo de inoculação, consumindo tempo no período crítico e curto de semeadura.

A eficácia dos produtos para adesão do inoculante à semente varia de acordo com o tipo de semente utilizada (Burton, 1976). Algumas substâncias utilizadas como adesivos mostraram toxidez, como o óleo diesel (Vargas et al., 1994); enquanto outras, como colas, leite, al gumas gomas, só ocasional mente resultaram em sucesso, mas há produtos com eficácia comprovada, como goma-arábica, polvilho deararuta (Maranta arundinaceae), polvilho de mandioca (Manihot esculenta), farinha de trigo (Triticum aestivum) e diversas celuloses e polímeros (Brockwell, 1962; Burton, 1964, 1981; National Academy of Sciences, 1979; F aria et al., 1985; Alcaraz, 1993/94; M or et al., 1995a, b; Y asuriyan et al., 1996).

Alguns adesivos, como a solução açucarada e outras gomas, também trazem benefícios pela mel hor distribuição e aumento na sobrevivência do rizóbio nas sementes, resultando em melhor desempenho simbiótico das plantas (Burton, 1964, 1981; Vincent, 1970; Peres et al., 1986; Mor et al., 1995a,b; Yasuriyan et al., 1996). Burton (1976) descreveu a superioridade da mistura de inoculante com solução de sacarose em relação ao inoculante com água, relatando ter encontrado o maior índice de sobrevivência do rizóbio nas sementes, quando foi utilizada uma concentração de $25 \%$ de sacarose.

Varma \& Subba Rao (1973) relataram que o nível máximo de sacarose no inoculante, para a obtenção de uma boa germinação da soja, seria de $5 \%$ e, quando esse nível fosse elevado para 10\%, haveria uma quebra acentuada na germi nação, uma redução no vigor das plântulas e um aumento na incidência de doenças fúngicas, pois os patógenos de sementes disporiam de fontes de carbono para a sua multiplicação. Entretanto, Vargas \& Suhet (1980), testando oi to formas eníveis de inoculação, relataram que o nível de $25 \%$ de sacarose não apresentou efeito negativo na germinação das sementes eas plântulas apresentaram desenvolvimento normal. Segundo os autores, a goma-arábica (sol ução a $40 \%$ ) ea sacarose (solução a 25\%) poderiam também ser adicionadas ao inoculante na proporção 1:1 (volume:peso), sendo essas formas de inoculação superiores à mistura simples do inoculante com água. A eficácia da utilização da solução de sacarose a $25 \%$ também foi confirmada, no Brasil, para a cultura do feijoeiro (Phaseol us vulgaris) (Mendes et al., 1994; Peres et al., 1994).

Com base nesses resultados, a recomendação da EMBRAPA (1994a,b), para a cultura da soja, no
Paraná ena região central do Brasil, atérecentemente, foi o uso de solu ção açucarada a $25 \%$. Contudo, essa prática vem sendo freqüentemente contestada por fitopatologistas, que temem pelo estímulo de bactérias e fungos patogênicos de sementes, com conseqüente quebra na taxa de germinação das sementes, embora não exista ensaio realizado no Brasil, com soja, para comprovar essa hipótese (Dr. A.A. Henning, comunicação pessoal).

Neste trabalho, procurou-se verificar, por meio de experimentos em laboratório, casa de vegetação e campo, a contribui ção da sol ução açucarada, a 25\% ou em doses inferiores, à fixação biológica do $\mathrm{N}_{2}$ para a cultura da soja.

\section{MATERIAL E MÉTODOS}

\section{Local da pesquisa}

Os estudos foram efetuados, entre 1994 e 1996, nos laboratórios, casa de vegetação, campo experimental da Embrapa - Centro Nacional de Pesquisa de Soja (E mbrapa Soja), em Londrina (PR), e no campo experimental da E mbrapa - Serviço de Produção de Sementes Básicas (E mbrapa Sementes Básicas), em Ponta Grossa (PR).

\section{Planta hospedeira}

Soja [Glycine max (L.) Merrill], cultivar BR-37, deciclo médio, recomendada para o estado do Paraná (EMBRAPA, 1994a).

\section{Estirpes e preparo do inoculante}

As estirpes de Bradyrhizobium utilizadas foram: (a) SEMIA 5019 (=29w), estirpe de Bradyrhizobium el kanii, de eficiência média a el evada, competitiva e recomendada, comercialmente, desde 1979; (b) SEMIA 587, outra estirpe de B. elkanii, eficiente, competitiva e recomendada, comercialmente, de 1968 até 1975 , e, novamente, a partir de 1979. As duas estirpes foram, original mente, fornecidas pela Fundação Estadual de Pesquisa Agropecuária FEPAGRO, Porto Alegre(RS).

A turfa utilizada foi fornecida pela Turfal Indústria e Comércio de Produtos Biológicos (Curitiba (PR)), com as especificações: (em g/100g): $\mathrm{N}$ total $(\mathrm{N})$ - 0,76; $\mathrm{P}$ total $\left(\mathrm{P}_{2} \mathrm{O}_{5}\right)-0,25 ; \mathrm{K}$ solúvel em água $\left(\mathrm{K}_{2} \mathrm{O}\right)$ - 0,28; matéria orgânica total - 34,7; $\mathrm{pH}$ em $\mathrm{CaCl}_{2}$ 0,001 M - 6,5; relação C/N - 25; umidadea $105^{\circ} \mathrm{C}-27,5 \%$; material retido em peneira ABNT $n^{\circ} 10(2,0$ mm) - 0,0\%; material retido em peneira ABNT $n^{\circ} 50$ (0,3 mm) - 2,63\%; fundo de peneira $97,37 \%$. A turfa (250 g por saco) foi acondicionada em sacos plásticos de polietileno e esterilizada em autoclave a $120^{\circ} \mathrm{C}, 1,01325 \times 10^{5} \mathrm{~Pa}$, por duas horas. Antes de preparar oinoculante, foi confirmado, pelo método de di luiçãoem placas (Andrade\& Hamakawa, 1984), que a turfa estava isenta de contaminantes. 
As estirpes cresceram em meio com extrato de levedura emanitol (YM, Vincent, 1970), por setedias, a $28^{\circ} \mathrm{C}$, quando atingiram a concentração de $10^{9}$ células $/ \mathrm{ml}$. Foram injetados, então, $80 \mathrm{ml}$ de cultura por saco de polietileno com $250 \mathrm{~g}$ de turfa esterilizada. Após a injeção da cultura de rizóbio, o orifício foi hermeticamente fechado com fita isol ante. Os sacos foram incubados a $28^{\circ} \mathrm{C} \pm 22^{\circ} \mathrm{C}$, por setedias, quando a concentração atingiu $10^{8}$ células/g de inoculante. Antes do plantio, a concentração de células do inoculante foi confirmada, por contagem em plantas (Andrade \& Hamakawa, 1994).

\section{Inoculação e doses de solução açucarada testadas}

Em todos os experimentos, a inoculação ocorreu conforme a recomendação da EMBRAPA (1994a,b), ou seja, na proporção de $500 \mathrm{ml}$ de solução açucarada, mais $500 \mathrm{~g}$ de inoculante turfoso, para $50 \mathrm{~kg}$ de sementes.

Foram testadas cinco concentrações de solução açucarada (açúcar comercial), como aderente do inoculante turfoso: 0, 10, 15, 20 e 25\%. As sementes não foram desinfectadas superficial mente antes da inoculação, para que possíveis patógenos de sementes não fossem eliminados.

\section{Determinação da adesividade do inoculante turfoso}

Dissolveu-se o açúcar, em quantidades tais para produzir as concentrações investigadas, em água, misturou-se ao inoculante turfoso e, a seguir, adicionaram-se as sementes de soja. Após três dias de secagem à temperatura ambiente $\left( \pm 25^{\circ} \mathrm{C}\right)$, as sementes foram retiradas, cuidadosamente, dos frascos. A remoção da turfa não aderida foi feita por lavagem com água à temperatura ambiente e, após o transporte para béckers pré-pesados, colocada em estufa até atingir massa constantee, então, pesada. Por outro lado, a remoção da turfa aderida às sementes foi feita com água quente $\left(90^{\circ} \mathrm{C} \pm 5^{\circ} \mathrm{C}\right)$ com tween (1\%), sendo também pesada após secagem. A soma da turfa não aderida com a turfa aderida resultou na soma da turfa adicionada às sementes, com um desvio máximo de $5 \%$. Os experimentos foram feitos em delineamento experimental inteiramente casualizado, com quatro repetições.

\section{Experimentos na casa de vegetação}

F rascos de vidro esterilizados - O efeito das doses de açúcar foi estudado em um sistema esterilizado, em frascos de vidro de $500 \mathrm{ml}$ de capacidade que continham $250 \mathrm{ml}$ de solução nutritiva isenta de N mineral e papel absorvente como suporte das plantas (Andrade \& Hamakawa, 1994). As sementes foram pré-germinadas por dois dias em câmara de germinação, procedendo-se ao plantio de uma semente pré-germinada de soja, com os diferentes tratamentos, por frasco. As plantas foram col etadas cinco semanas após a emergência.
Vasos com solo não esterilizado - As sementes inoculadas foram plantadas em vasos quecontinham $2,5 \mathrm{~kg}$ de solo (Latossolo Roxo), com população de 105 células de Bradyrhizobium/g de solo, avaliada em plantas de soja, cultivar BR-37, segundo Andrade \& Hamakawa (1994). A análise química do solo consta do quadro 1. Foram plantadas cinco sementes por vaso, procedendo-se ao desbaste uma semana após o plantio, deixando-se duas plantas por vaso. Incluíram-se control es não inoculados, com e sem a adição de $40 \mathrm{mg} \mathrm{N} /$ planta/semana, como nitrato de potássio $\left(\mathrm{KNO}_{3}\right)$. As plantas foram coletadas cinco semanas após a emergência.

Vasos de Leonard - Este experimento teve, como objetivo, testar o efeito do tempo de armazenamento, de 0-8 dias, das sementes inoculadas com soluções açucaradas a 15 e $25 \%$, na nodulação e no crescimento das plantas. As plantas foram col etadas quatro semanas após a emergência.

Os experimentos foram realizados em delineamento experimental de blocos ao acaso, com cinco repeti ções, para os frascos devidro esterilizados, e quatro repetições, para os experimentos em vasos de L eonard e em vasos com solo não esterilizado.

Nas col etas, as plantas foram separadas em parte aérea eraiz, na altura do nó cotiledonar. O material foi seco em estufa, a $65^{\circ} \mathrm{C}$, até atingir massa constante. Os nódulos foram coletados das raízes, contados, secos e pesados. $\mathrm{O} \mathrm{N}$ total da parte aérea foi avaliado pel o método espectrofotométrico do azul de indofenol, segundo Feije \& Anger (1972).

\section{Experimentos no campo}

Os experimentos foram efetuados em um Latossolo Roxo ( $L R$ ), em Londrina, e em um Latossol o Vermelho-E scuro (LVe), em Ponta Grossa, nas safras de 1994/1995 e de 1995/1996. As propriedades químicas e o número de células de Bradyrhizobium dos solos constam do quadro 1. A calagem (2 t ha-1, em L ondrina, e 4 t ha-1, em Ponta Grossa), e a adubação foram realizadas conforme análise química, corrigindo-se para todos os macronutrientes, exceto $\mathrm{N}$, na quantidade de $300 \mathrm{~kg}$ ha-1 de N-P-K (0-28-20). Adicionaram-se, ainda, $30 \mathrm{~kg} \mathrm{ha}-1$ de micronutrientes (FTE-BR-12, óxido silicatado contendo, em \%: Zn - 90; B - 1,80; Cu - 0,8; Fe- 3,0; Mn - 2,0; Mo - 0,10).

A inoculação foi efetuada na mesma proporção de solução açucarada, inoculante e semente, usada anteriormente, tendo sido incluído um control e sem inoculação.

As parcelas experimentais mediram 3,0 $2,0 \mathrm{~m}$, com 0,5 m entrelinhas e foram separadas por 2,0 m e por pequenos terraços, para evitar contaminação. Os experimentos foram real izadas em delineamento em blocos ao acaso, com seis repetições. Não houve irrigação na época de semeadura ou durante os experimentos. 
Quadro 1. Análise química e número de células de Bradyrhizobium , na camada de $0-20 \mathrm{~cm}$, do Latossolo Roxo (LR), região de Londrina, utilizado nos experimentos de casa de vegetação, e do $L R$, região de Londrina, e do Latossolo Vermel ho-E scuro (LVe), região de Ponta Grossa, uti lizados nos experimentos de campo nas safras de 1994/1995 e 1995/1996

\begin{tabular}{|c|c|c|c|c|c|}
\hline \multirow{3}{*}{ Característica } & \multirow{3}{*}{$\begin{array}{c}\text { Casa de vegetação } \\
\text { (LR) }\end{array}$} & \multicolumn{4}{|c|}{ Campo } \\
\hline & & \multicolumn{2}{|c|}{ 94/95 } & \multicolumn{2}{|c|}{ 95/96 } \\
\hline & & $\begin{array}{l}\text { Londrina } \\
\text { (LR) }\end{array}$ & $\begin{array}{c}\text { Ponta Grossa } \\
\text { (LVe) }\end{array}$ & $\begin{array}{l}\text { Londrina } \\
\text { (LR) }\end{array}$ & $\begin{array}{c}\text { Ponta Grossa } \\
\text { (Lve) }\end{array}$ \\
\hline $\mathrm{pH}$ em $\mathrm{CaCl}_{2}$ & 5,30 & 4,89 & & 4,70 & 4,89 \\
\hline$N\left(g / d^{3}\right)$ & 0,18 & 0,15 & 0,12 & 0,15 & 0,13 \\
\hline Al $\left(\mathrm{cmol}^{\prime} / \mathrm{dm}^{3}\right)$ & 0,07 & 0,07 & 0,15 & 0,12 & 0,01 \\
\hline $\mathrm{K}\left(\mathrm{cmol}_{\mathrm{c}} / \mathrm{dm}^{3}\right)$ & 0,52 & 0,56 & 0,35 & 0,32 & 0,25 \\
\hline $\mathrm{Ca}\left(\mathrm{cmol}_{\mathrm{c}} / \mathrm{dm}^{3}\right)$ & 4,71 & 4,68 & 3,52 & 3,04 & 3,19 \\
\hline $\mathrm{Mg}\left(\mathrm{cmol}_{\mathrm{c}} / \mathrm{dm}^{3}\right)$ & 1,52 & 1,69 & 1,62 & 1,55 & 2,05 \\
\hline $\mathrm{H}+\mathrm{Al}\left(\mathrm{cmol}_{\mathrm{c}} / \mathrm{dm}^{3}\right)$ & 3,33 & 3,08 & 4,82 & 5,23 & 5,71 \\
\hline Al $\left(\mathrm{cmol}_{\mathrm{c}} / \mathrm{dm}^{3}\right)$ & 1,03 & 1,00 & 2,66 & 2,38 & 0,18 \\
\hline $\mathrm{C}\left(\mathrm{g} / \mathrm{dm}^{3}\right)$ & 1,80 & 1,75 & 1,17 & 1,21 & 2,36 \\
\hline $\mathrm{P}\left(\mathrm{mg} / \mathrm{dm}^{3}\right)$ & 13,2 & 11,4 & 8,82 & 9,4 & 7,0 \\
\hline $\begin{array}{l}\text { Bradyrhizobium } \\
\text { (n。cél./g de terra) }\end{array}$ & $10^{5}$ & $10^{5}$ & $10^{3}$ & $10^{5}$ & $10^{3}$ \\
\hline
\end{tabular}

Na safra 1994/1995, foram amostradas dez plantas por repetição, em duas épocas decol eta para cada local, no estádio vegetativo(V3, três nós no caule principal com folhas plenamente desenvolvidas, escala de Fehr \& Caviness, 1977) e no início do florescimento (R2), em Londrina, e no estádio vegetativo (V3) e de formação das vagens (R4), em Ponta Grossa. Nas coletas, as plantas foram separadas em parte aérea eraiz e o material foi seco em estufa, a $65^{\circ} \mathrm{C}$, até atingir massa constante. Os nódul os foram col etados das raízes, contados, secos e pesados. O N total da parte aérea foi avaliado conforme já descrito.

$\mathrm{Na}$ col eta final, nas duas safras, foram avaliados o rendimento eo $\mathrm{N}$ total dos grãos. O rendimento foi corrigido para $13 \%$ de umidade, após leitura em um aparel ho determinador de umidade Vurroughf 700.

\section{Análise estatística}

Os dados foram submetidos à análise de variância. As médias dos dados de laboratório ecasa de vegetação foram comparadas pel o teste de Tukey, a $5 \%$. As médias dos dados de campo foram comparadas pelo teste de Duncan a $5 \%$. Foram utilizados os programas SANEST-PC (Zonta et al., 1982) eSAS para Macintosh.

\section{RESULTADOS}

Em relação à concentração de açúcar, o emprego deuma solução açucarada a $10 \%$ já foi suficiente para aderir oinoculanteturfoso às sementes, incrementando em $90 \%$ (de 48,2 para 91,5\%) a aderência em relação à inoculação exclusivamente com água. Não foram detectadas diferenças estatísticas entre as concentrações de solução açucarada testadas, embora maior aderência tenha ocorrido nas concentrações de 10 e 15\% (Quadro 2). Pelos resultados obtidos, portanto, não restam dúvidas sobre a importância da solução açucarada como aderente, visto que a quantidade total de inoculante turfoso aderido às sementes aumentou de $241 \mathrm{~g}$, quando somenteágua foi utilizada, para $458 \mathrm{~g}$, na concentração de $10 \%$ (Quadro 2).

Nos experimentos em casa de vegetação, em frascos esterilizados, com plantas recebendo solução nutritiva isenta de $\mathrm{N}$, o número de nódulos foi superior com o uso de sol ução açucarada a 15, 20 e 25\% (Quadro 3). A massa nodular ea da parteaérea não diferiram, estatisticamente, entre as doses de açúcar testadas, mas todas foram superiores às do tratamento em que o inoculante turfoso foi aderido somente com água. Em relação ao $\mathrm{N}$ total fixado, os mel hores resultados também foram obtidos com as concentrações de 20, 25 e 15\% de açúcar, com um destaque para 20\% (Quadro 3). Dessemodo, a solução açucarada a $20 \%$ permitiu um acúmulo denitrogênio total da parte aérea superior em 108\% em relação à adesão exclusivamente com água (Quadro 3).

Em condições mais próximas às encontradas no campo, no experimento realizado em vasos com solo não esterilizado, o mai or número de nódul os ocorreu com o uso de sol ução açucarada a 10\% (Quadro 4). 
Quadro 2. Efeito da concentração de solução açucarada na aderência do inoculante turfoso às sementes de soja, cv. BR-37. Experimento realizado em laboratório, utilizando a proporção de $500 \mathrm{ml}$ de solução açucarada: $500 \mathrm{~g}$ de inoculante turfoso: $50 \mathrm{~kg}$ de sementes

\begin{tabular}{ccc}
\hline $\begin{array}{c}\text { Solução } \\
\text { açucarada }\end{array}$ & $\begin{array}{c}\text { Aderência } \\
\text { as sementes }\end{array}$ & $\begin{array}{c}\text { Total do inoculante } \\
\text { aderido }\end{array}$ \\
\hline & $\%$ & $\mathrm{~g}$ \\
0 & $48,2 \mathrm{~b}^{(1)}$ & $241,0 \mathrm{~b}$ \\
10 & $91,5 \mathrm{a}$ & $457,5 \mathrm{a}$ \\
15 & $92,0 \mathrm{a}$ & $460,0 \mathrm{a}$ \\
20 & $88,0 \mathrm{a}$ & $440,0 \mathrm{a}$ \\
25 & $80,9 \mathrm{a}$ & $404,5 \mathrm{a}$ \\
C.V. (\%) & 13,0 & 14,0
\end{tabular}

(1) Médias de quatro repetições e, quando seguidas pela mesma letra, não diferem estatisticamente pelo teste de Tukey (5\%).

Quadro 3. E feito da concentração de solução açucarada, como aderente de inoculante turfoso com as estirpes SEMIA 587 e SE MIA 5019 ( $10^{8}$ células/g de inoculante), na nodulação e acúmulo de massa e $\mathbf{N}$ total da parte aérea de soja, cultivar BR-37. 0 inoculante foi adicionado na proporção de 500 $\mathrm{ml}$ de solução açucarada: $\mathbf{5 0 0} \mathrm{g}$ de inoculante: $50 \mathrm{~kg}$ de sementes. 0 experimento foi realizado em um sistema esterilizado, com frascos de vidro que continham solução nutritiva isenta de $\mathbf{N}$ e as plantas foram coletadas cinco semanas após a emergência

\begin{tabular}{|c|c|c|c|c|}
\hline \multirow{2}{*}{$\begin{array}{l}\text { Solução } \\
\text { açucarada }\end{array}$} & \multicolumn{2}{|c|}{ Nodulação } & \multicolumn{2}{|c|}{ Parte aérea } \\
\hline & Número & Massa & Massa & $\mathbf{N}$ total \\
\hline$\%$ & n\%/planta & $\mathrm{mg} /$ planta & g/planta & $\mathrm{mg} \mathrm{N} / \mathrm{planta}$ \\
\hline $\begin{array}{r}0 \\
10 \\
15 \\
20 \\
25\end{array}$ & $\begin{array}{l}12,1 b^{(1)} \\
17,4 b^{2} \\
30,2 \mathrm{a} \\
29,8 \mathrm{a} \\
27,6 \mathrm{a}\end{array}$ & $\begin{array}{l}23,3 \mathrm{~b} \\
37,8 \mathrm{a} \\
40,1 \mathrm{a} \\
43,5 \mathrm{a} \\
41,4 \mathrm{a}\end{array}$ & $\begin{array}{l}0,32 \mathrm{~b} \\
0,42 \mathrm{a} \\
0,49 \mathrm{a} \\
0,48 \mathrm{a} \\
0,42 \mathrm{a}\end{array}$ & $\begin{array}{c}7,8 \mathrm{c} \\
10,2 \mathrm{bc} \\
12,6 \mathrm{ab} \\
16,2 \mathrm{a} \\
14,5 \mathrm{ab}\end{array}$ \\
\hline C.V. (\%) & 21,4 & 25,4 & 9,6 & 8,8 \\
\hline
\end{tabular}

(1) Médias de cinco repetições e, quando seguidas pela mesma letra, não diferem estatisticamente pelo teste de Tukey (5\%).

Os tratamentos com açúcar favoreceram o acúmulo de N na parte aérea, embora não fossem detectadas diferenças estatísticas em relação à inoculação com água. Como exemplo, os tratamentos com solução a 10 e $15 \%$ superaram o $\mathrm{N}$ da parte aérea do tratamento comágua em 44 e $22 \%$, respectivamente (Quadro 4).
Quadro 4. Efeito da concentração de solução açucarada, como aderente de inoculante turfoso com as estirpes SEMIA 587 e SE MI A 5019 ( $10^{8}$ células $/ g$ de inoculante), na nodulação e acúmulo de massa e $\mathbf{N}$ total da parte aérea de soja, cultivar BR-37. 0 inoculante foi adicionado na proporção de $500 \mathrm{ml}$ de solução açucarada: $500 \mathrm{~g}$ de inoculante: $50 \mathrm{~kg}$ de semente. 0 experimento foi realizado em vasos que continham LR com população estabelecida $\left(10^{5}\right.$ células de Bradyrhizobium/g de solo) e as plantas foram coletadas cinco semanas após a emergência

\begin{tabular}{|c|c|c|c|c|}
\hline \multirow{2}{*}{$\begin{array}{c}\text { Solução } \\
\text { açucarada }\end{array}$} & \multicolumn{2}{|c|}{ Nodulação } & \multicolumn{2}{|c|}{ Parte aérea } \\
\hline & Número & Massa & Massa & $\mathbf{N}$ total \\
\hline$\%$ & n\%/planta & mg/planta & g/planta & $\mathrm{mg} \mathrm{N} / \mathrm{planta}$ \\
\hline $\begin{array}{r}0 \\
10 \\
15 \\
20 \\
25\end{array}$ & $\begin{array}{l}38,0 b^{(1)} \\
58,2 a \\
39,5 \mathrm{~b} \\
44,8 \mathrm{ab} \\
38,2 \mathrm{~b}\end{array}$ & $\begin{array}{l}60,0 \text { a } \\
88,9 \text { a } \\
61,5 \text { a } \\
71,4 \text { a } \\
58,9 \text { a }\end{array}$ & $\begin{array}{l}0,85 \mathrm{a} \\
1,08 \mathrm{a} \\
0,92 \mathrm{a} \\
1,01 \mathrm{a} \\
1,07 \mathrm{a}\end{array}$ & $\begin{array}{l}18,5 \mathrm{a} \\
26,7 \mathrm{a} \\
22,6 \mathrm{a} \\
21,8 \mathrm{a} \\
24,9 \mathrm{a}\end{array}$ \\
\hline $\mathrm{T}^{2}$ & $37,8 \mathrm{~b}$ & $60,6 \mathrm{a}$ & $0,85 a$ & $18,8 \mathrm{a}$ \\
\hline $\mathrm{T}+\mathrm{N}^{(2)}$ & $33,5 \mathrm{~b}$ & $32,3 \mathrm{~b}$ & $0,85 a$ & $25,2 \mathrm{a}$ \\
\hline C.V. (\%) & 27,3 & 25,0 & 13,8 & 10,9 \\
\hline
\end{tabular}

(1) Médias de quatro repetições e, quando seguidas pela mesma letra, não diferem estatisticamente pelo teste de Tukey (5\%). (2) Testemunha sem inoculação, sem (T) e com (T +N) 40 mg N $\left(\mathrm{KNO}_{3}\right) /$ planta/semana.

Em termos de recomendação, outra preocupação freqüente refere-se ao tempo de armazenamento máximo permitido após a inoculação com solução açucarada. Os resultados obtidos em casa de vegetação indicaram que essas sementes podem ser armazenadas, com segurança, por um período de três dias, sem redução da nodulação e $\mathrm{N}$ total da parte aérea (Quadro 5).

No campo, na safra 1994/1995, em Londrina, em um solo com população el evada de Bradyrhizobium (105 células/g de solo, Quadro 1), não foi constatado efeito da inoculação no número e massa nodular (Quadro 6). No início do florescimento, embora não houvesse diferença estatística no $\mathrm{N}$ total da parte aérea , a utilização de solução açucarada a 10, 15 e $20 \%$ resultou em incrementos de 21,23 e $27 \%$, respectivamente, em rel ação à inocul ação exclusivamenteem queutilizou-seágua. Na coleta final, o maior rendimento e $\mathrm{N}$ total dos grãos foram obtidos no tratamento com sol uçãoaçucarada a 10\% (Quadro 6).

Na safra 1994/1995, em Ponta Grossa, no estádio vegetativo, em um $L$ Vecom população de $10^{3}$ células deBradyrhizobium/g (Quadro 1), também não houve diferença estatística, entre os tratamentos, nas características de nodulação (Quadro 7). No período de formação das vagens, porém, constatou-se que a 
concentração de $10 \%$ resultou em mai or acúmulo de $\mathrm{N}$ na parte aérea. $\mathrm{Na}$ coleta final, a inoculação sempre resultou em incremento no rendimento dos grãos e, embora não diferindo estatisticamente do tratamento com água, a solução açucarada proporcionou rendimentos e $\mathrm{N}$ total dos grãos mais elevados (Quadro 7).

Quadro 5. Efeito do tempo de armazenamento após a inoculação ( $500 \mathrm{~g}$ de solução açucarada a 15 ou 25\%: 500 g de inoculante: 50 kg de sementes) na massa de nódulos secos (MNS) e $\mathbf{N}$ total acumulado na parte aérea (NTPA) de soja, cv. BR-37. Experimento realizado em vasos de Leonard $e$ as plantas foram coletadas quatro semanas após emergência; inoculante que continha estirpes SE MIA 587 e SEMIA 5019

\begin{tabular}{ccc}
\hline Tempo de armazenamento & \multicolumn{1}{c}{ MNS } & NTPA \\
\hline dias & mg/planta & $\mathrm{mg} \mathrm{N} /$ planta \\
0 & $51,5 \mathrm{ab}(1)$ & $13,4 \mathrm{ab}$ \\
1 & $62,3 \mathrm{a}$ & $15,1 \mathrm{ab}$ \\
2 & $57,7 \mathrm{ab}$ & $13,5 \mathrm{ab}$ \\
3 & $62,1 \mathrm{a}$ & $17,0 \mathrm{a}$ \\
4 & $53,1 \mathrm{ab}$ & $15,3 \mathrm{ab}$ \\
5 & $47,7 \mathrm{ab}$ & $14,4 \mathrm{ab}$ \\
6 & $44,0 \mathrm{~b}$ & $11,2 \mathrm{~b}$ \\
7 & $52,9 \mathrm{ab}$ & $16,6 \mathrm{a}$ \\
8 & $52,8 \mathrm{ab}$ & $13,9 \mathrm{ab}$ \\
C.V. (\%) & 26,4 & 24,6
\end{tabular}

(1) Os dados foram submetidos a uma análise conjunta e repre sentam médias de oito repetições, quatro a $15 \%$ e quatro a $25 \%$. Médias seguidas pela mesma letra não diferem, estatisticamente, pelo teste de Tukey (5\%).
Da safra 1995/1996, são apresentados somente os resultados relativos ao rendimento e $\mathrm{N}$ total acumulado nos grãos de soja. Em Londrina, os maiores rendimentos e teores de $\mathrm{N}$ total nos grãos foram obtidos com a adição de sol ução açucarada a 10 e 15\% (Quadro 8). E m Ponta Grossa, novamente com menor número de células de Bradyrhizobium estabelecidas no solo, a inoculação, ainda que sem aderente, garantiu incrementos el evados no rendimento. Os incrementos no rendimento, pela adição de solução açucarada, em relação à testemunha com população naturalizada, chegaram a 23\% (solução açucarada a 20\%) ede 16\% em relação ao teor deN total nos grãos (Quadro 8). Em nenhum dos experimentos no campo, realizados nos dois locais, por duas safras, foi constatada perda do poder de germinação, menor vigor das plântulas ou maior incidência de doenças pela adição de solução açucarada, o que refletiu em rendimentos adequados.

Foi realizada, então, uma análise conjunta, para cada local e para os dois locais, dos experimentos de duas safras. Em Londrina, incrementos significativos no rendimento de grãos foram obtidos pelo uso de sol ução açucarada a 10\% (Quadro 9). Em Ponta Grossa, foi detectado o efeito benéfico da inoculação, mas não houve incremento, estatisticamente significativo, pela adição de açúcar, embora os rendimentos tenham sido numericamente superiores aos da inoculação com água (Quadro 9). Consi derando os quatro experimentos realizados no campo, durante duas safras, a reinoculação com solução açucarada a $10 \%$ resultou em um incremento, estatisticamentesignificativo, de $8,6 \%$, em relação à reinoculação com água, e de $17,5 \%$, em relação ao controle com a população estabel ecida do solo.

Quadro 6. Efeito da concentração de solução açucarada, como aderente de inoculante turfoso com as estirpes SE MIA 587 e SE MIA 5019 (108 células/g de inoculante), no número (NN) e massa de nódulos secos (MNS) na coleta realizada no estádio vegetativo; no $\mathbf{N}$ total acumulado na parte aérea (NTPA) de plantas, coletadas no início do florescimento e no rendimento e N total dos grãos (NTG) de soja, cultivar BR-37. Experimento realizado em Londrina, na safra 1994/1995, em um LR com população naturalizada ( $10^{5}$ células de Bradyrhizobium/g de solo). A inoculação foi realizada na proporção de $500 \mathrm{ml}$ de solução açucarada: $500 \mathrm{~g}$ de inoculante: 50 kg de sementes

\begin{tabular}{|c|c|c|c|c|c|}
\hline \multirow{2}{*}{ Solução açucarada } & \multicolumn{2}{|c|}{ Vegetativo } & \multirow{2}{*}{$\frac{\text { Florescimento }}{\text { NTPA }}$} & \multicolumn{2}{|c|}{ Coleta final } \\
\hline & $\mathbf{N N}$ & MNS & & Rendimento(1) & NTG \\
\hline$\%$ & no/planta & mg/planta & $\mathrm{mg} \mathrm{N} / \mathrm{planta}$ & $\mathrm{kg} \mathrm{ha}^{-1}$ & $\mathrm{~kg} \mathrm{ha}^{-1} \mathrm{~N}$ \\
\hline $\begin{array}{r}0 \\
10 \\
15 \\
20 \\
25\end{array}$ & $\begin{array}{l}15,7 \mathrm{a}^{(2)} \\
16,2 \mathrm{a} \\
16,0 \mathrm{a} \\
14,0 \mathrm{a} \\
15,2 \mathrm{a}\end{array}$ & $\begin{array}{r}11,0 \mathrm{a} \\
9,9 \mathrm{a} \\
10,4 \mathrm{a} \\
8,9 \mathrm{a} \\
9,8 \mathrm{a}\end{array}$ & $\begin{array}{r}88,4 \mathrm{a} \\
107,0 \mathrm{a} \\
108,8 \mathrm{a} \\
112,2 \mathrm{a} \\
94,8 \mathrm{a}\end{array}$ & $\begin{array}{l}2.629 \mathrm{~b} \\
2.951 \mathrm{a} \\
2.568 \mathrm{~b} \\
2.681 \mathrm{ab} \\
2.711 \mathrm{ab}\end{array}$ & $\begin{array}{l}135,1 \mathrm{ab} \\
151,1 \mathrm{a} \\
128,4 \mathrm{~b} \\
135,6 \mathrm{ab} \\
137,4 \mathrm{ab}\end{array}$ \\
\hline $\mathrm{T}^{(3)}$ & $17,8 \mathrm{a}$ & 13,8 a & 93,0 a & $2.816 \mathrm{ab}$ & $140,8 \mathrm{ab}$ \\
\hline C.V. (\%) & 16,7 & 30,2 & 27,2 & 9,3 & 9,7 \\
\hline
\end{tabular}

(1) Rendimento de grãos corrigido para 13\% de umidade. ${ }^{(2)}$ Os valores representam médias de seis repetições e, quando seguidos pela mesma letra, não diferem estatisticamente, pelo teste de Duncan, a 5\%. ${ }^{(3)}$ Testemunha sem inoculação. 
Quadro 7. Efeito da concentração de solução açucarada, como aderente de inoculante turfoso com as estirpes SE MIA 587 e SE MIA 5019 ( $10^{8}$ células/g de inoculante), no número (NN) e massa de nódulos secos (MNS) na coleta realizada no estádio vegetativo; no $\mathbf{N}$ total acumulado na parte aérea (NTPA) de plantas, coletadas no estádio de formação das vagens e no rendimento e $\mathbf{N}$ total dos grãos (NTG) de soja, cultivar BR-37. Experimento conduzido em Ponta Grossa, na safra 1994/1995, em um LVe com população naturalizada ( $10^{3}$ células de Bradyrhizobium/g de solo). A inoculação foi realizada na proporção de $500 \mathrm{ml}$ de solução açucarada: $500 \mathrm{~g}$ de inoculante: 50 kg de sementes

\begin{tabular}{|c|c|c|c|c|c|}
\hline \multirow{2}{*}{ Solução açucarada } & \multicolumn{2}{|c|}{ Vegetativo } & \multirow{2}{*}{$\frac{\text { Formação das vagens }}{\text { NTPA }}$} & \multicolumn{2}{|c|}{ Coleta final } \\
\hline & $\mathrm{NN}$ & MNS & & Rendimento(1) & NTG \\
\hline$\%$ & no/planta & mg/planta & $\mathrm{mg} \mathrm{N} /$ planta & kg ha-1 & $\mathrm{kg} \mathrm{ha}^{-1} \mathrm{~N}$ \\
\hline $\begin{array}{r}0 \\
10 \\
15 \\
20 \\
25\end{array}$ & $\begin{array}{l}15,5 \mathrm{a}^{2} \\
14,6 \mathrm{a} \\
13,6 \mathrm{a} \\
15,3 \mathrm{a} \\
14,7 \mathrm{a}\end{array}$ & $\begin{array}{l}11,3 \text { a } \\
11,4 \text { a } \\
11,2 \text { a } \\
14,2 \text { a } \\
12,9 \text { a }\end{array}$ & $\begin{array}{l}227,6 \mathrm{~b} \\
319,6 \mathrm{a} \\
279,2 \mathrm{ab} \\
286,0 \mathrm{ab} \\
280,6 \mathrm{ab}\end{array}$ & $\begin{array}{l}2.290 \mathrm{a} \\
2.312 \mathrm{a} \\
2.406 \mathrm{a} \\
2.393 \mathrm{a} \\
2.353 \mathrm{a}\end{array}$ & $\begin{array}{l}118,6 \mathrm{ab} \\
124,2 \mathrm{a} \\
129,5 \mathrm{a} \\
124,7 \mathrm{a} \\
129,5 \mathrm{a}\end{array}$ \\
\hline$T^{(3)}$ & $12,5 \mathrm{a}$ & 14,5 a & $163,6 \mathrm{~b}$ & $1.942 \mathrm{~b}$ & $102,7 \mathrm{~b}$ \\
\hline C.V. (\%) & 21,7 & 26,8 & 26,4 & 11,4 & 12,2 \\
\hline
\end{tabular}

(1) Rendimento de grãos corrigido para 13\% de umidade. ${ }^{(2)}$ Os valores representam médias de seis repetições e, quando seguidos pela mesma letra, não diferem estatisticamente, pelo teste de Duncan, a 5\%. ${ }^{(3)}$ Testemunha sem inoculação.

Quadro 8. Efeito da concentração de solução açucarada, como aderente de inoculante turfoso com as estirpes SE MIA 587 e SE MIA 5019 ( $10^{8}$ células/g de inoculante), no rendimento e $\mathbf{N}$ total dos grãos (NTG) de soja, cultivar BR-37. Experimentos conduzidos na safra 1995/1996, em Londrina, em um LR com população naturalizada ( $10^{5}$ células de Bradyrhizobium/g de solo) e em Ponta Grossa, em um LVe com população naturalizada ( $10^{3}$ células de Bradyrhizobium/g de solo). A inoculação foi realizada na proporção de $500 \mathrm{ml}$ de solução açucarada: $500 \mathrm{~g}$ de inoculante: 50 kg de sementes

\begin{tabular}{|c|c|c|c|c|}
\hline \multirow{2}{*}{ Solução açucarada } & \multicolumn{2}{|c|}{ Londrina } & \multicolumn{2}{|c|}{ Ponta Grossa } \\
\hline & Rendimento(1) & NTG & Rendimento(1) & NTG \\
\hline$\%$ & kg ha-1 & $\mathrm{kg} \mathrm{ha}^{-1} \mathrm{~N}$ & $\mathrm{~kg} \mathrm{ha}^{-1}$ & $\mathrm{~kg} \mathrm{ha}^{-1} \mathrm{~N}$ \\
\hline $\begin{array}{r}0 \\
10 \\
15 \\
20 \\
25\end{array}$ & $\begin{array}{l}2.839 \mathrm{bc}^{(2)} \\
3.261 \mathrm{a} \\
3.308 \mathrm{a} \\
2.949 \mathrm{~b} \\
3.096 \mathrm{ab}\end{array}$ & $\begin{array}{l}161,3 \mathrm{~b} \\
202,4 \mathrm{a} \\
208,2 \mathrm{a} \\
199,1 \mathrm{a} \\
186,4 \mathrm{a}\end{array}$ & $\begin{array}{l}3.239 a \\
3.420 a \\
3.205 a \\
3.508 a \\
3.254 a\end{array}$ & $\begin{array}{l}173,2 \mathrm{~b} \\
170,2 \mathrm{~b} \\
179,4 \mathrm{~b} \\
196,6 \mathrm{a} \\
184,8 \mathrm{ab}\end{array}$ \\
\hline$T^{(3)}$ & $2.555 c$ & $153,3 \mathrm{~b}$ & $2.855 \mathrm{~b}$ & 169,7 b \\
\hline C.V. (\%) & 9,8 & 6,3 & 5,0 & 5,5 \\
\hline
\end{tabular}

(1) Rendimento de grãos corrigidos para 13\% de umidade. ${ }^{(2)}$ Os valores representam médias de seis repetições e, quando seguidos pela mesma letra, não diferem estatisticamente, pelo teste de Duncan, a 5\%. ${ }^{(3)}$ Testemunha sem inoculação.

\section{DISCUSSÃO}

Atualmente, são comercializados, no Brasil, para a cultura da soja, 12,3 milhões de doses de inoculante, a maioria em sacos de turfa de $250 \mathrm{~g}$ (Hungria et al., 1999). A boa aderência da turfa às sementes, porém, é essencial ao sucesso do processo de inoculação. No caso do Brasil, quando comparado a países com temperaturas mais baixas, como a Argentina, Uruguai, EUA e Canadá, o problema é ainda maior, pois a turfa nacional é de qualidade inferior, tanto em termos nutricionais, como em características físicas, apresentando teores mais elevados de areia, que promovem menor aderência às sementes. Nesse contexto, diversos estudos têm procurado identificar, tanto no exterior como no 
Quadro 9. Efeito da concentração de solução açucarada, como aderente de inoculante turfoso com as estirpes SEMIA 587 e SE MIA 5019 ( $10^{8}$ células $/ g$ de inoculante), no rendimento de grãos (corrigido para $13 \%$ de umidade) de soja, cv. BR-37, em solos do Paraná com população estabelecida de Bradyrhizobium. A inoculação foi realizada na proporção de $500 \mathrm{ml}$ de solução açucarada: $500 \mathrm{~g}$ de inoculante: $50 \mathrm{~kg}$ de sementes

\begin{tabular}{clcc}
\hline $\begin{array}{c}\text { Solução } \\
\text { açucarada }\end{array}$ & Londrina & $\begin{array}{c}\text { Ponta } \\
\text { Grossa }\end{array}$ & $\begin{array}{c}\text { Média dos quatro } \\
\text { experimentos }\end{array}$ \\
\hline$\%$ & & $\mathrm{~kg} \mathrm{ha}^{-1}$ & \\
\cline { 2 - 4 } 0 & $2.734 \mathrm{~b}^{(1)}$ & $2.764 \mathrm{a}$ & $2.749 \mathrm{~b}$ \\
10 & $3.106 \mathrm{a}$ & $2.866 \mathrm{a}$ & $2.986 \mathrm{a}$ \\
15 & $2.938 \mathrm{ab}$ & $2.806 \mathrm{a}$ & $2.872 \mathrm{ab}$ \\
20 & $2.815 \mathrm{ab}$ & $2.950 \mathrm{a}$ & $2.882 \mathrm{ab}$ \\
25 & $2.904 \mathrm{ab}$ & $2.804 \mathrm{a}$ & $2.854 \mathrm{ab}$ \\
$\mathrm{T}^{(2)}$ & $2.686 \mathrm{~b}$ & $2.398 \mathrm{~b}$ & $2.542 \mathrm{c}$ \\
\end{tabular}

(1) Os dados representam médias de dois experimentos realizados, em cada local, com seis repetições, nas safras de 1994/1995 e 1995/1996. Quando seguidos pela mesma letra, não diferem estatisticamente, peloteste de Duncan, a 5\%. ${ }^{(2)}$ Testemunha sem inoculação.

Brasil, substâncias que promovam a aderência dos inoculantes turfosos às sementes (Burton, 1976; National Academy of Sciences, 1979; Faria et al., 1985; Peres et al., 1986, 1994; Vargas et al., 1990; Alcaraz, 1993/94; Mendes et al., 1994; Mor et al., 1995a,b; Yasuriyan et al., 1996).

Estudos brasileiros já identificaram algumas substâncias com boa capacidade adesiva, como a goma-arábica (Vargas \& Suhet, 1980; Faria et al., 1985; Vargas et al., 1990), polvilho de araruta, polvil ho de mandioca e farinha de trigo (F aria et al., 1985). Em escala comercial, porém, o uso de diversos desses produtos fica limitado. A goma-arábica encontrada no mercado, por exemplo, éinadequada para a inoculação, pois contém fungicidas e bactericidas destinados à sua conservação (Faria et al., 1985). Ao contrário, o açúcar comercial é um produto com qualidade homogênea, baixo custo, isento de substâncias tóxicas e pode ser encontrado em qualquer local.

Em experimento realizado nos cerrados com feijoeiro (Vargas et al., 1990), o uso de inóculo com solução de sacarose (provavel mente açúcar comercial) a $25 \%$ mostrou mel hor rendimento de grãos, embora nãoapresentasse diferença estatística com a goma-arábica. Esse resultado da solução açucarada a $25 \%$ pode ser comparado com os obtidos, recentemente, por Mendes et al. (1994) e Peres et al .
(1994), também com o feijoeiro, com bons rendimentos quando esta solução foi utilizada com $1.000 \mathrm{~g}$ de inoculante e $40 \mathrm{~kg}$ de sementes, nos cerrados. Nesses experimentos com feijoei ro (Vargas et al., 1990; Mendes et al., 1994; Peres et al., 1994), porém, não foram utilizadas concentrações de solução açucarada inferiores a $25 \%$, tampouco foi relatado aumento na incidência de doenças ou decréscimo no vigor das plântulas.

No caso da soja, também em solos de Cerrado, Vargas \& Suhet (1980) relataram que a gomaarábica, a $40 \%$, ou sacarose, a $25 \%$, foram eficazes. Posteriormente, Vargas et al. (1982) obtiveram bons resultados, no campo, com sacarose a $25 \%$ utilizada com $1.000 \mathrm{~g}$ de inoculante e $40 \mathrm{~kg}$ de sementes de soja. Nãohá menção, também, à incidência de doenças ou problemas no vigor das plântulas. Concentraçõ̃es inferiores a $25 \%$, porém, não foram testadas por esse autores, tornando difícil a comparação com os resultados obtidos nestetrabal ho, com doses inferiores.

Com basenos resultados obtidos nos experimentos conduzidos pela E mbrapa Cerrados, na recomendação para a cultura da soja, para a Região Central e para - Paraná, consta, como adesivo para inoculante turfoso, solução de sacarose a 25\% (EMBRAPA, 1994a,b). Contudo, segundo muitos fitopatologistas, a concentração de $25 \%$ acarretaria grande quantidade de carbono disponível, que estimularia bactérias e fungos patogênicos de sementes, prejudicando sua emergência, embora não exista nenhum ensaio realizado no Brasil, com soja, para comprovar essa hipótese (Dr. A.A. Henning, comunicação pessoal). Mesmo assim, passou a ser recomendado que, no caso de uso de solução açucarada, o tratamento com fungicidas deve ser obrigatório(EMBRAPA, 1996a,b).

Todavia, conformejá mencionado, ouso de sol ução açucarada, mesmo a $25 \%$, tanto nos ensaios nos Cerrados, como neste trabal ho, não provocou maior incidência de doenças de sementes ou diminuição do vigor das plantas. Os ensaios realizados em Londrina e Ponta Grossa, por duas safras, nãoforam irrigados, refletindo as condições normalmente encontradas pelo agricultor. Contudo, o açúcar, por representar mais um insumo para oagricultor e para garantir que não haverá problemas fitossanitários ou de vigor das plântulas, os experimentos deste estudo visaram verificar os efeitos dedoses inferiores de solução açucarada. A importância do estudo é ainda maior quando se considera que a adição da dose de $25 \%$ vem sendo, freqüentemente, utilizada como justificativa para incrementar o tratamento obrigatório de sementes com fungi cidas (REUNIÃO... 1997; EMBRAPA, 1998a,b) que, por sua toxidez, podem diminuir drasticamente a nodulação no campo (Campo \& Hungria, 1999).

Nesse contexto, os resultados deste trabalho indicam quea concentração da solução açucarada pode ser de $10 \%$. Os resultados aqui apresentados foram obtidos com sementes não tratadas com fungicidas, 
mas outros ensaios mostraram que os efeitos são extensivos aos dois tipos de sementes (dados não mostrados).

Muitas vezes, o agricultor não consegue plantar no mesmo dia em que realizou o tratamento de sementes e, no caso de sementes tratadas com solução açucarada, existe, ainda, a preocupação de aumento na incidência de doenças. Peres et al. (1986) mostraram, porém, que, até oito dias após a inoculação das sementes não tratadas com fungicidas, mesmo com solução açucarada, a viabilidade do inoculante foi mantida. Neste trabalho, os resultados obtidos mostraram que as sementes inoculadas com sol ução açucarada podem ser estocadas por três dias, tendo-se até constatado um aumento na nodulação, provavelmente pelo efeito positivo do açúcar na sobrevivência do rizóbio, conforme mencionado por Burton (1976).

A falta de esclarecimento aos agricultores decorre do fato de não ser comum a prática de adesivos no processo de inoculação. Os resultados encontrados neste trabalho, porém, mostram a importância do uso de um adesivo, no caso solução açucarada, para a aderência do inoculante turfoso, em especial com a turfa brasileira, que tem menor poder de adesividade às sementes de soja. Na ausência desse adesivo, o agricultor poderá estar desperdiçando até metade do inoculanteadquirido. Os benefícios do uso da solução açucarada foram evidenciados em experimentos de laboratório, casa devegetação eem campo.

No caso dos solos de Londrina, com uma população naturalizada el evada deBradyrhizobium (105 células/g de solo), o adesivo resultou em incrementos no rendimento da soja. Em Ponta Grossa, em um solo com menor número de anos sob cultivo e, portanto, com menor população (103 células/g de solo), a inoculação com água já foi suficientepara obter uma boa nodulaçãoe rendimento. Contudo, deve-se considerar que, com o cultivo sucessivo da soja, a população naturalizada do solo tende a aumentar; conseqüentemente, a mai or adesão doinoculanteàs sementes auxiliará no estabel ecimento dos rizóbios carregados no inoculante. O efeito benéfico do adesivo foi confirmado, ainda, na análise conjunta dos quatro experimentos, constando-se que a solução açucarada resultou em um incremento médio de $8,6 \%$ no rendimento da cultura.

Estetrabal ho confirma, também, os benefícios da reinoculação para a cultura da soja, em relação à nodulação e fixação de $\mathrm{N}_{2}$ proporcionadas pela população naturalizada. Esses benefícios foram constatados tanto em Londrina como em Ponta Grossa, confirmando resultados obtidos no Paraná ena região Central (Nishi \& Hungria, 1996; Hungria et al., 1997; 1999; Vargas \& Hungria, 1997; Araújo \& Hungria, 1999). A rei noculação com o uso de adesivos é, portanto, uma prática importante para maximizar o fornecimento de $\mathrm{N}$ à cultura da soja, garantindo bons rendimentos.

\section{CONCLUSÕES}

1. A solução açucarada, usada para aderir o inoculante turfoso, favoreceu a aderência do inoculante às sementes de soja, a nodulação e o rendimento da cultura.

2. A solução açucarada a $10 \%$ foi suficiente para garantir a aderência do inoculante turfoso, a boa nodulação, a fixação do nitrogênio e o rendimento da soja.

\section{AGRADECIMENTOS}

Aos funcionários do Laboratório de Microbiologia do Solo da E mbrapa Soja, Lígia Maria deO. Chueire e Rinaldo B. Conceição, pelo auxílio técnico na realização dos experimentos. Aos técnicos agrícolas, J osé Zucca Morais e Rubson N. R. Sibaldelli, pelo auxílio nos experimentos em campo. À pesquisadora M. C. Neves de Oliveira, pelo auxílio nas análises estatísticas. Ao prof. Dr. É dison Miglioranza (UEL) e ao Dr. Rubens J . Campo (Embrapa Soja), pelas sugestões e discussão do manuscrito. O. Brandão J unior agradece à CAPES, pela bolsa de mestrado, e $\mathrm{M}$. Hungria, ao CNPq, pela bolsa de produtividade em pesquisa (520396/96-0). Trabalho financiado parcialmente pelo CNPq (520396/96-0) e FINEP/ CNPq/MCT, Grupo de Excelência em Fixação do Nitrogênio (41.96.0884.00).

\section{LITE RATURA CITADA}

ALCARAZ, M.M.; PASTOR, M.D. \& BALATTI, A.P. Cinética de sobrevivência de Rhizobium meliloti B-36 sobre semilla preinoculada com diferentes adhesivos y coberturas. R. Fac. Agron., 14:167-171, 1993/94.

ANDRADE, D.S. \& HAMAKAWA, P.J . Estimativa do número de células viáveis de rizóbio, no solo e em inoculantes por infecção em plantas. In: HUNGRIA, M. \& ARAUJ O, R.S., eds. Manual de métodos empregados em estudos de microbiologia agrícola. Brasília, Empresa Brasileira de Pesquisa Agropecuária, 1994. p.63-94.

ARAÚJ O, F.F. \& HUNGRIA, M. Nodulação erendimento de soja co-inoculada com Bacillus subtilis e Bradyrhizobium japonicum/ B. elkanii. Pesq. Agropec. Bras., 34:1633-1643, 1999.

BROCKWELL, J . Studies on seed pelleting as an aid on legume seed inoculation. I. Coating materials, adhesives and methods of inoculation. Aust. J. Agric. Res., 13:638-640, 1962.

BURTON, J.C. Methods of inoculating seeds and their effect on survival of rhizobia. In: NUTMAN, P.S., ed. Symbiotic nitrogen fixation in plants. Cambridge, Cambridge University Press, 1976. p.175-189. 
BURTON, J.C. Rhizobium - legume association. In: GI LMOUR, G.M. \& ALLEN, N., eds. Microbiology and soil fertility. Oregon, Oregon State University, 1964. p.107-134.

BURTON, J.C. Rhizobium inoculants for developing countries. Trop. Agric., 58:291-295, 1981.

CAMPO, R.J . \& HUNGRIA, M. Efeito dotratamento de sementes de soja com fungicidas na nodulação e fixação simbiótica do $\mathrm{N}_{2}$. Londrina, Empresa Brasileira de Pesquisa Agropecuária, 1999. 7p. (EMBRAPA Soja. Pesquisa em Andamento, 21)

EMPRESA BRASILEIRA DE PESQUISA AGROPECUÁRIA EMBRAPA. Centro Nacional de Pesquisa de Soja. Recomendações técnicas para a cultura da soja no Paraná - 1994/95. Cascavel, 1994a. 140p. (EMBRAPA-CNPSo. Documentos, 79)

EMPRESA BRASILEIRA DE PESQUISA AGROPECUÁRIA EMBRAPA. Centro Nacional de Pesquisa de Soja. Recomendações técnicas para a cultura da soja na Região Central do Brasil - 1994/95. Londrina, 1994b. 127p. (EMBRAPA-CNPSo. Documentos, 77)

EMPRESA BRASILEIRA DE PESQUISA AGROPECUÁRIA EMBRAPA. Centro Nacional de Pesquisa de Soja. Recomendações técnicas para a cultura da soja na Região Central do Brasil - 1996/97. Londrina, 1996a. 164p. (EMBRAPA-CNPSo. Documentos, 96)

EMPRESA BRASILEIRA DE PESQUISA AGROPECUÁRIA EMBRAPA. Centro Nacional de Pesquisa de Soja. Recomendações técnicas para a cultura da soja no Paraná - 1996/97. Londrina, 1996b. 187p. (EMBRAPA-CNPSo. Documentos, 97)

EMPRESA BRASILEIRA DE PESQUISA AGROPECUÁRIA EMBRAPA. Centro Nacional de Pesquisa de Soja. Recomendações técnicas para a cultura da soja no Paraná - 1998/99. Londrina, 1998a. 201p. (EMBRAPA-CNPSo. Documentos, 119)

EMPRESA BRASILEIRA DE PESQUISA AGROPECUÁRIA EMBRAPA. Centro Nacional de Pesquisa de Soja (EMBRAPA-CNPSo). Recomendações técnicas para a cultura da soja na Região Central do Brasil - 1998/99. Londrina, 1998b. 182p. (EMBRAPA-CNPSo. Documentos, 120)

FAO (Rome, Italy). Quart. Bull. Stat., 10:56, 1997.

FARIA, S.M.D.; DE-POLLI, H. \& FRANCO, A.A. Adesivos para inoculação e revestimento de sementes de leguminosas. Pesq. Agropec. Bras., 20:169-176, 1985.

FEHR, W.R. \& CAVINESS, C.E. Stages of soybean devel opment. Ames, I owa State University, 1977. (Special Report, 80)

FEIJ E, F. \& ANGER, V. Spots tests in inorganic analyses. Anal. Chem. Acta, 149:363-367, 1972.

FONTES, R.M.O. \& FERRÃO, P.R. Competitividade da soja brasileira no mercado internacional. In: CONGRESSO BRASILEIRO DE ECONOMIA E SOCIOLOGIA RURAL, 28., Florianópolis, 1990. Anais. Brasília, Sociedade Brasileira de E conomia eSociologia Rural, 1990. p.149-162.

HUNGRIA, M.; VARGAS, M.A.T.; ANDRADE, D.S.; CAMPO, R.J .; CHUEIRE, L.M.O.; FERREIRA, M.C. \& MENDES, I.C. Fixação biológica do nitrogênio em leguminosas de grãos. In: FERTBIO. Anais. Lavras, Universidade Federal de Lavras, 1999. p.597-620.
HUNGRIA, M.; VARGAS, M.A.T. \& CAMPO, R.J . A inoculação da soja. Londrina, Empresa Brasileira de Pesquisa Agropecuária, 1997. 28p. (EMBRAPA-CNPSo. Circular Técnica, 17; EMBRAPA-CPAC. Circular Técnica, 34)

J OLY, C. Biological nitrogen fixation within FAO agricultural production programmes in the context of sustainable development. Rome, FAO, 1991. p.9-14.

MENDES, I.C.; SUHET, A.R.; PERES, J .R.R. \& VARGAS, M.A.T. Eficiência fixadora de estirpes de rizóbio em duas cultivares de feijoeiro. R. Bras. Ci. Solo, 18:421-425, 1994.

MOR, S.; DOGRA, R.S. \& DUDEJ A, S.S. Effect of adhesives on rhizobial survival, distribution, nodulation and nitrogen fixation in summer and winter legumes. Ind. J . Microbiol., 35:115-120, 1995a.

MOR, S.; DOGRA, R.S. \& SINGH, K. Effect of adhesives on nitrogen fixation in legumes and cereals. Leg. Res., 18:200204, 1995b.

NATIONAL ACADEMY OF SCIENCES. Washington, EUA. Tropical legumes: resourcefor the future. Washington, 1979. p.278-283.

NISHI, C.Y.M. \& HUNGRIA, M. Efeito da reinoculação na soja [Glycine max (L.) Merril] em um solo com população estabelecida de Bradyrhizobium com as estirpes SEMIA 566, 586, 587, 5019, 5079 e 5080. Pesq. Agropec. Bras., 31:359-368, 1996.

PERES, J .R.R.; SUHET, A.R.; MENDES, I.C. \& VARGAS, M.A.T. Efeito da inoculação com rizóbio e da adubação nitrogenada em sete cultivares de feijão em solo de Cerrado. R. Bras. Ci. Solo, 18:415-420, 1994.

PERES, J .R.R.; SUHET, A.R. \& VARGAS, M.A.T. Sobrevivência de estirpes de Rhizobium japonicum na superfície de sementes de soja inoculadas. Pesq. Agropec. Bras., 21:489493, 1986.

REUNIÃO DE PESQUISA DE SOJ A DA REGIÃO SUL, 25, PasSo Fundo, 1997. Recomendações técnicas para a cultura da soja no Rio Grande do Sul e em Santa Catarina - 1997/98. Passo Fundo, EMBRAPA-CNPT, 1997. 130p.

ROESSING, A.C. \& GUEDES, L.C.A. Aspectos econômicos do complexo soja: sua participação na economia brasileira e evolução na região do Brasil Central. In: ARANTES, N.E. $\&$ SOUZA, P.I.M., eds. Cultura da soja nos cerrados. Piracicaba, POTAFOS, 1993. p.1-69.

RONCHI, A.L. \& BALATTI, A.P. Selección de soportes para la producción de inoculantes para leguminosas. R. Fac. Agron., 12:209-217, 1991.

SMITH, R.S. I noculant formulations and applications to meet changing needs. In: TIKHONOVICH, I.A.; PROVOROV, N.A.; ROMANOV, V.I. \& NEWTON, W.E., eds. Nitrogen fixation: fundamentals and applications. Dordrecht, Kluwer Academic Publishers, 1995. p.653-657.

SOMASEGARAN, P. Inoculant production with emphasis on choice of carriers, methods of production and reliability testing/quality assurance guidelines. Rome, FAO, 1991. p.87-105.

VARGAS, A.A.T.; ATHAYDE, J .T. \& GRAHAM, P.H. Métodos de inoculação do feijoeiro com Rhizobium leguminosarum bv phaseoli. R. Microbiol., 21:5-10, 1990. 
VARGAS, M.A.T. \& HUNGRIA, M. Fixação biológica do nitrogênio na cultura da soja. In: VARGAS, M.A.T. \& HUNGRIA, M., eds. Biologia dos solos dos Cerrados. Planaltina, Empresa Brasileira de Pesquisa Agropecuária, 1997. p.297-360.

VARGAS, M.A.T.; PERES,J .R.R. \& SUHET, A.R. Adubação nitroge nada, inoculação e épocas de calagem para a soja em um sol o sob Cerrado. Pesq. Agropec. Bras., 17:1127-1132, 1982.

VARGAS, M.A.T. \& SUHET, A.R. Efeito de tipos e níveis de inoculantes na soja cultivada em um sol o de Cerrado. Pesq. Agropec. Bras., 15: 343-347, 1980.

VARGAS, M.A.T.; SUHET, A.R., MENDES, I.C. \& PERES, J .R.R. Fixação biológica de nitrogênio em solos de Cerrados. Brasília, Empresa Brasileira de Pesquisa Agropecuária, 1994. 83p.
VARMA, A.K. \& SUBBA RAO, N.S. Sucrose and application of Rhizobium on seed. Plant Soil, 38:227-230, 1973.

VINCENT, J .M. Manual for the practical study of root nodule bacteria. Oxford, Blackwell Scientific Publications, 1970. 164p. (IBP Handbook, 15).

YASURIYAN, V.; HAMEED, M.S. \& RAJ, S.A. Influence of adhesives and timelag between seed treatment and sowing on survival of rhizobia and crop response to inoculation. Madras Agric. J ., 83:488-490, 1996.

ZONTA, E.P.; MACHADO, A.A. \& SILVEIRA J UNIOR, P. Sistema de análise estatística - SANEST. Pelotas, 1982. Registro SEI nº66060. 